\title{
Impact of Diuretics on Metabolic Activity of Urogenital Tract Microbiota in Women
}

\author{
Amar Balihodžić, Nadira Ibrišimović Mehmedinović, Suada Tinjić, Semira Galijašević, Kamelija \\ Madacki-Todorović, Izet Eminović, Lejla Hasanbegović, Mirza Ibrišimović
}

\begin{abstract}
Limited knowledge exists about the effects of commonly used diuretic medications on the human normal flora. Thus, we investigated potential stimulatory effects of diuretic drug furosemide on urogenital tract microbiota in women. Three strains of E. coli and C. albicans with different biofilm forming capacities were obtained from female patients diagnosed with urinary tract infections. All tested strains were treated with two different concentrations of furosemide drug, in comparison to non-treated strains as the negative control. At specific time intervals, samples were obtained from growing culture and analyzed for their proliferation rate, aspartyl proteinase excretion and biofilm formation ability. $E$. coli and $C$. albicans strains significantly increased their aspartyl proteinase excretion under furosemide treatment. This effect was frequently observed after 16 hours of incubation at $37^{\circ} \mathrm{C}$. This drug has also increased the biofilm forming capacities of E. coli and C. albicans strains. Interestingly, both $E$. coli and C. albicans non-biofilm former strains, gained the capacity of biofilm formation when treated with furosemide at certain concentrations. E. coli control became a weak biofilm former after 48 hours of incubation, while non-biofilm former $C$. albicans strain became a weak biofilm former in dose-dependent fashion, after 48 hours incubation with furosemide in concentration of $0.1 \mathrm{mg} / \mathrm{mL}$, and after 16 hours of incubation with furosemide in concentration of $0.5 \mathrm{mg} / \mathrm{mL}$. Loop diuretic drug furosemide is able to increase the microbial virulence and turn commensal microbes into opportunistic pathogens. Additionally, the results suggest that enzyme aspartyl
\end{abstract}

Manuscript received on July 18, 2021.

Revised Manuscript received on August 01, 2021.

Manuscript published on October 30, 2021.

* Correspondence Author

Amar Balihodžić*, Sarajevo Medical School, University Sarajevo School of Science and Technology, Sarajevo, Bosnia and Herzegovina Email: amar.balihodzic@protonmail.com

Nadira Ibrišimović Mehmedinović, Department of Chemistry, Faculty of Natural Science and Mathematics, University of Tuzla, Tuzla, Bosnia and Herzegovina. Email: nadira.ibrisimovic@untz.ba

Suada Tinjić, Gynecology Polyclinic "Korak do života”, Tuzla, Bosnia and Herzegovina. Email: suada.tinjic@gmail.com

Semira Galijašević, Sarajevo Medical School, University Sarajevo School of Science and Technology, Sarajevo, Bosnia and Herzegovina. Email: semira.galijasevic@ssst.edu.ba

Kamelija Madacki-Todorović, Sarajevo Medical School, University Sarajevo School of Science and Technology, Sarajevo, Bosnia and Herzegovina. Email: kamelija.madacki@ssst.edu.ba

Izet Eminović, Faculty of Natural Science and Mathematics, University of Sarajevo, Sarajevo, Bosnia and Herzegovina. Email: eminovicizet@gmail.com

Lejla Hasanbegović, Biochemical-Immunological-Hemathological "Medical Laboratory" Ilidža, Sarajevo, Bosnia and Herzegovina. Email hasanbegoviclejla2001@gmail.com

Mirza Ibrišimović, Gynecology Polyclinic "Korak do života", Tuzla, Bosnia and Herzegovina and Sarajevo Medical School, University Sarajevo School of Science and Technology. Email: mirza.ibrisimovic@ssst.edu.ba

(c) The Authors. Published by Blue Eyes Intelligence Engineering and Sciences Publication (BEIESP). This is an open access article under the CC BY-NC-ND license (http://creativecommons.org/licenses/by-nc-nd/4.0/) proteinase might act as a signal molecule for the biofilm formation, leading to the increased microbial pathogenicity.

Keywords: aspartyl proteinase, biofilm, C. albicans, E. coli, furosemide.

\section{INTRODUCTION}

I L oop diuretics are frequent drugs in the treatment of different conditions which can cause the buildup of fluid in the body, and are the choice of therapy in heart failure, kidney or liver diseases [1]. Types of loop diuretics are furosemide, bumetanide, and torsemide, and they are quickly absorbed after oral administration, within 0.5-2 hours (2). Diuretic drugs have different pharmacokinetics and pharmacodynamics and can even cause anaphylactic reactions in some patients. However, that is not an obstacle for many clinicians to use them in some stereotyped manner [2,3]. There are several studies which indicate a tight connection between diuretics use and their effects on gastrointestinal microbiota, including their contribution to the spontaneous bacterial peritonitis occurrence in cirrhotic patients [4]. However, there are no published data about potential effects of diuretics on microbiota of urogenital tract. Since the administration of diuretics can cause gender-related differences by which women need lower doses of diuretics $[5,6]$, we focused our study on microbial strains derived from female patients affected with urinary tract infections (UTIs) as more dominant type of infections in this population $[7,8]$. Escherichia coli (E. coli) is one of the leading cause of UTIs, which does not only colonize vaginal epithelium but has the ability to reside inside the vaginal cells as well [9]. In some studies it was reported that $E$. coli under influence of certain drugs can change its metabolic activities and start producing virulent factors in form of enzymes or extracellular proteins such as $\alpha$-hemolysin $[10,11]$. On the other side, also Candida species, including Candida albicans, are uropathogenes causing serious infections of urinary tract [12]. Considering emerging studies that demonstrate indirect roles of ordinarily used medications in clinical settings on normal flora, we intended to explore the potential effect of furosemide on urogenital tract microbiota in women. Additional aim was to describe the potential microbial metabolic and structural adaptations.

Published By:

Blue Eyes Intelligence Engineering and Sciences Publication (BEIESP)

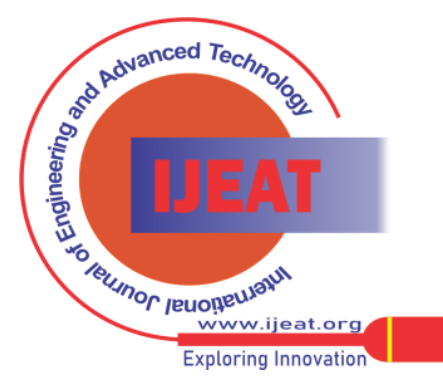




\section{METHODS}

\section{A. Microbial strains}

Three strains of Escherichia coli (E. coli 8, E. coli 9, E. coli control) and three strains of Candida albicans $(C$. albicans 3 and C. albicans 4, C. albicans 6) were obtained from samples of hospitalized female patients diagnosed with UTIs using standard microbiological isolation and identification approached based on colony morphology on blood and MacConkey agar (Sigma-Aldrich, Vienna, Austria).

E. coli 8, E. coli 9 and C. albicans 3, C. albicans 4 had a strong biofilm forming capacity. E. coli control and $C$. albicans 6 are strains without biofilm forming capacity. Additionally, all strains of these microorganisms without furosemide supplementation were used as negative control. E. coli strains were grown in trypticase soy broth (TSB) medium (Sigma-Aldrich, Vienna, Austria), while C. albicans strains were grown in Sabouraud 2\%-glucose broth (Sigma-Aldrich, Vienna, Austria). The microbes were cultured at standard aerobic conditions at $37^{\circ} \mathrm{C}$.

\section{B. Generation of growth curves}

$10 \mu \mathrm{L}$ of over-night culture of every $E$. coli and C. albicans strain, were inoculated in sterile plastic $15 \mathrm{~mL}$ tubes containing $3 \mathrm{~mL}$ of respective growth media. The cultures were growing at $37^{\circ} \mathrm{C}$ for different incubation times: $0 \mathrm{~h}, 8 \mathrm{~h}$, $16 \mathrm{~h}, 24 \mathrm{~h}$ and $48 \mathrm{~h}$. Prior to incubation, furosemide of two different concentrations, $0.1 \mathrm{mg} / \mathrm{mL}$ and $0.5 \mathrm{mg} / \mathrm{mL}$, was added into each test tube containing specific microorganisms. Optical density for each test sample and each incubation time was measured at $600 \mathrm{~nm}$. The obtained values were used for generation of growth curves.

\section{Aspartyl proteinase assay}

Following the incubation, $100 \mu \mathrm{L}$ of microbial culture was pooled out and mixed with $400 \mu \mathrm{L}$ of $1 \%$ bovine serum albumin (BSA; Sigma-Aldrich, Vienna, Austria) and incubated at $37^{\circ} \mathrm{C}$ for 30 minutes. The reaction was stopped by adding $1 \mathrm{~mL}$ of $10 \%$ trifluoroacetic acid (Sigma-Aldrich, Vienna, Austria). Both, 1\% BSA and 10\% trifluoroacetic acid, were previously diluted in $0.1 \mathrm{M}$ citrate buffer ( $\mathrm{pH}$ 3.5).

Afterwards, the samples were centrifugated for 10 minutes at $1000 \mathrm{rpm}$. The resulting supernatant containing aspartyl proteinase was isolated.

\section{Determination of aspartyl proteinase concentration}

The concentration of aspartyl proteinase was evaluated with spectrophotometer (Multiskan GO, Thermo Scientific, Waltham, Massachusetts, USA).

Absorbance of test samples was measured at $260 \mathrm{~nm}$ and $280 \mathrm{~nm}$, according to Warburg Christian. The final calculations were carried out according to the following equation: $\mathrm{mg}$ of protein $/ \mathrm{mL}=1.55$ x A280 - 0.76 x A260.

\section{E. Biofilm forming capacity test}

Test tubes containing the microorganisms whose growth has been stopped at different incubation times were pooled out from expanding cultures and washed with phosphate buffered saline (PBS), pH 7.5.

Afterwards, the tubes were inverted for about 20 minutes to air-dry. $1 \mathrm{~mL}$ of $0.1 \%$ crystal violet (Sigma-Aldrich, Vienna, Austria) was then added. The tubes were cautiously rotated to assure crystal violet reaches all cells attached to the test tube walls.

Following the 5 minutes incubation, the crystal violet was removed and tubes were washed with $\mathrm{dH} 2 \mathrm{O}$. Test tubes were finally analyzed for the biofilm formation. Samples were classified as weak, moderate and strong biofilm formers based on the shade of the film and sum of the cells.

\section{F. Statistical analysis}

Depicted data are disclosed as mean \pm standard deviation (SD). Datasets are analyzed using student's t-test and one-way ANOVA corrected with Bonferroni post hoc test. A p-value less than 0.05 was considered statistically significant. Results were depicted in tables and graphs created by Microsoft Office (2019, Microsoft, Redmond, Washington, USA).

\section{RESULTS}

\section{A. Effects of furosemide administration of microbial proliferation}

Amongst the most crucial features of microorganisms is their competence to grow and replicate. They do that in various environments. Increased proliferation is possible only if environment is supportive, rich in food and lacks inhibitory substances.

Logarithmic phase of growth for all three strains of $E$. coli was clearly established after 8 hours of incubation at $37^{\circ} \mathrm{C}$. In the following incubation periods, proliferation trend remained similar for the negative control and treated samples (Figure 1). Similar pattern was observed in two C. albicans strains. C. albicans 3 exhibited the slowest growth of all tested strains. There were no differences in the growth pattern among the tested groups.

Likewise, growing $C$. albicans 4 strain reached the logarithmic phase after 8 hours of incubation and continued to proliferate similarly throughout the later incubation periods. Interestingly, $C$. albicans 6 without treatment showed a higher proliferation in the earlier time points, after 8 and 16 hours of incubation.

However, C. albicans 6 under furosemide of both concentrations started to proliferate more at 24 hours, while that difference was significantly higher at 48 hours of incubation (Figure 2).

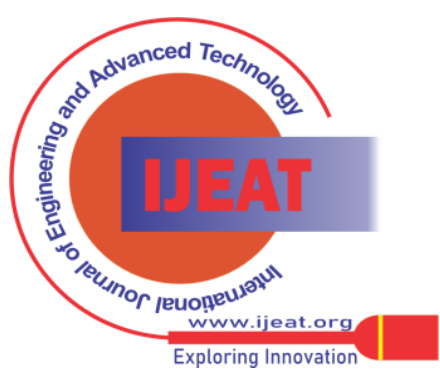



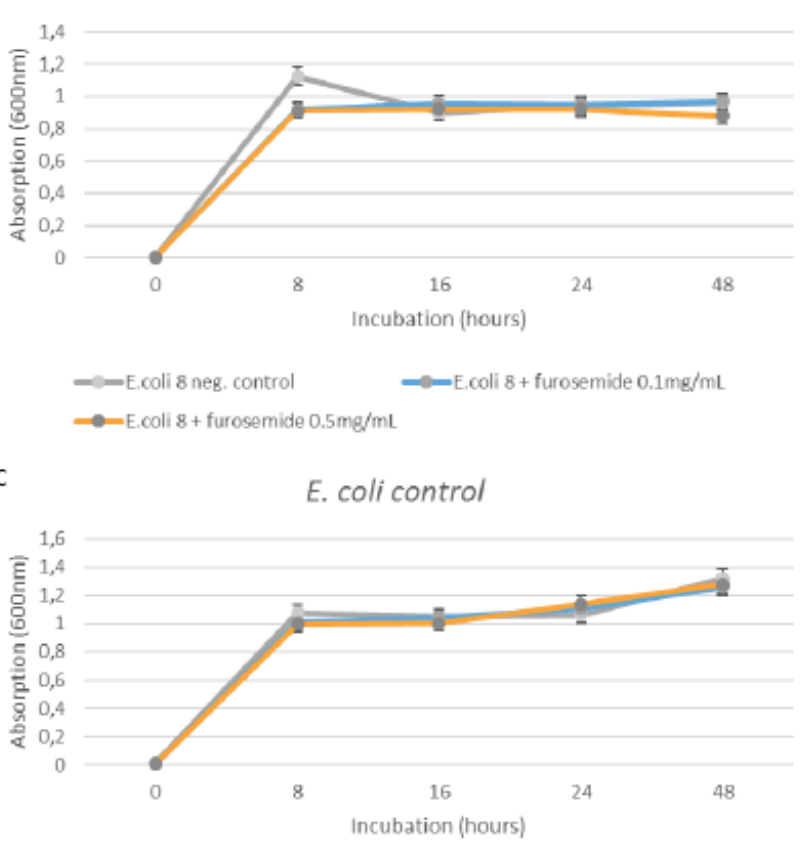

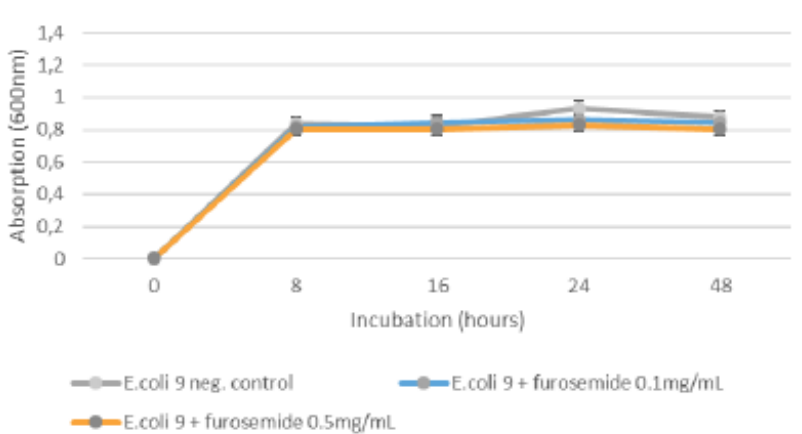

Figure 1 (A, B, C). Effect of furosemide on $\boldsymbol{E}$. coli proliferation. There were no differences in the growth pattern among the tested groups. Logarithmic phase of growth was established after 8 hours. In the following incubation periods, proliferation rate remained similar in all groups.

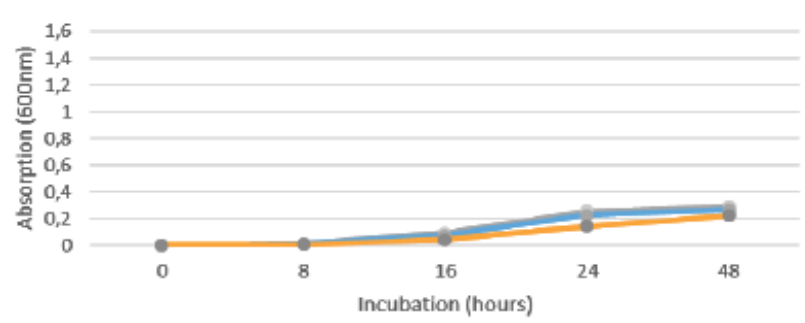

-C.albicans 3 neg control $\rightarrow$ C.albicans $3+$ furosemide $0.5 \mathrm{mg} / \mathrm{mL}$

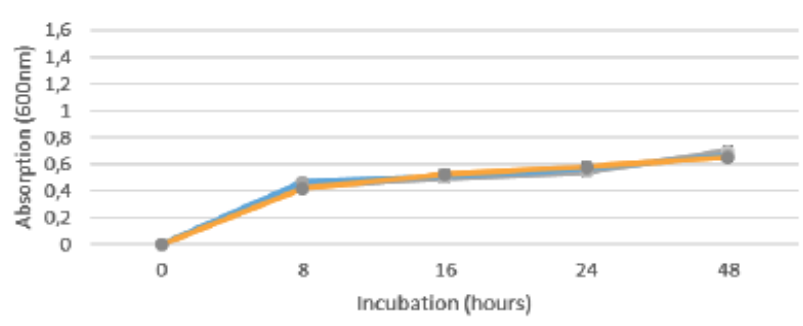

-C.albicans 4 neg control $\leadsto$ C.albicans $4+$ furosemide $0.1 \mathrm{mg} / \mathrm{mL}$

C

C. albicans 6

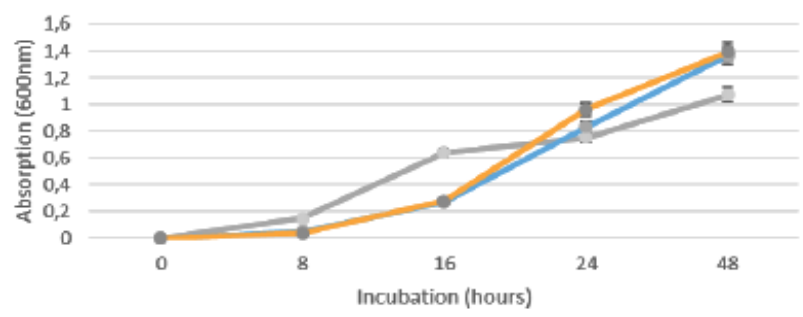

-C.albicans 6 neg. control

-C.albicans 6 + furosemide $0.1 \mathrm{mg} / \mathrm{mL}$

$\rightarrow-$ C.albicans $6+$ fur osemide $0.5 \mathrm{mg} / \mathrm{mL}$

Figure 2 (A, B, C). Effect of furosemide on C. albicans proliferation. A: C. albicans 3 exhibited the slowest growth, with no differences in three tested groups. B: C. albicans 4 strain reached the logarithmic phase after 8 hours of incubation and continued to proliferate similarly throughout the later incubation periods. C: Non-treated C. albicans 6 exhibited higher proliferation in earlier time points. However, furosemide increased the proliferation of C. albicans 6 after 24 hours and 48 hours of incubation.

Published By:

Blue Eyes Intelligence Engineering and Sciences Publication (BEIESP) 29 (C) Copyright: All rights reserved.

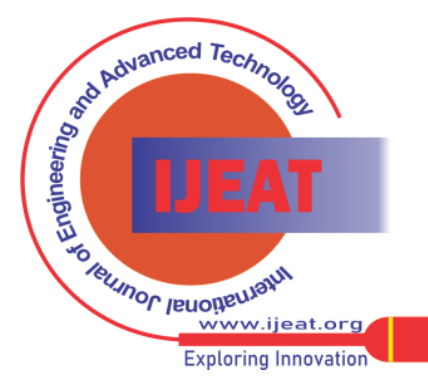




\section{B. Effects of furosemide administration on microbial aspartyl proteinase excretion}

Administration of furosemide in two dosing concentrations of $0.1 \mathrm{mg} / \mathrm{mL}$ and $0.5 \mathrm{mg} / \mathrm{mL}$ enhanced metabolic activity of some E. coli and C. albicans strains. Increased aspartyl proteinase excretion was observed frequently after 16 hours of incubation, while some differences may be explained with intrinsic characteristics of the tested strains. Furosemide had a stimulatory effect on $E$. coli 8 metabolic activity at two incubation times. Significant excretion was observed after 16 and 48 hours of incubation with concentration of $0.5 \mathrm{mg} / \mathrm{mL}$ and $0.1 \mathrm{mg} / \mathrm{mL}$, respectively. The similar results were observed in E. coli 9 strain. Dose-dependent effect on aspartyl proteinase$$
\text { A }
$$
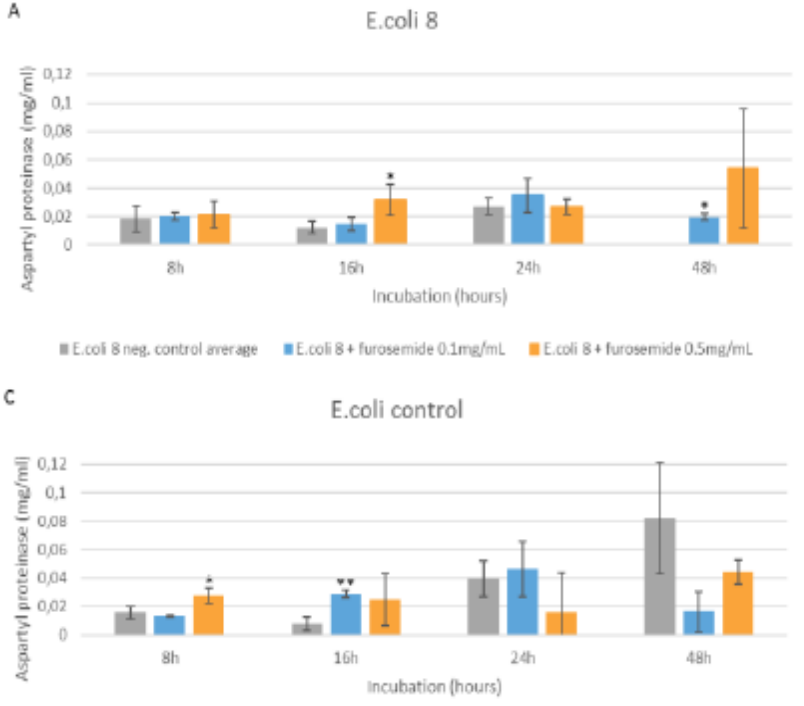

excretion was observed after 16 hours of incubation. Metabolic activity of $E$. coli control was significantly altered by furosemide after 8 and 16 hours of incubation (Figure 3). However, furosemide exhibited more striking metabolic changes on $C$. albicans strains. Furosemide increased the aspartyl proteinase excretion in C. albicans 4 throughout the entire incubation periods in dose-dependent fashion. Nonetheless, significant effect was observed after 48 hours of incubation in $C$. albicans 3 strain. Interestingly, the metabolism of non-biofilm former C. albicans 6 was upregulated under furosemide treatment after 16 hours of incubation and persisted during the entire experiment. This stimulatory effect was also noted in dose-depended fashion (Figure 4).

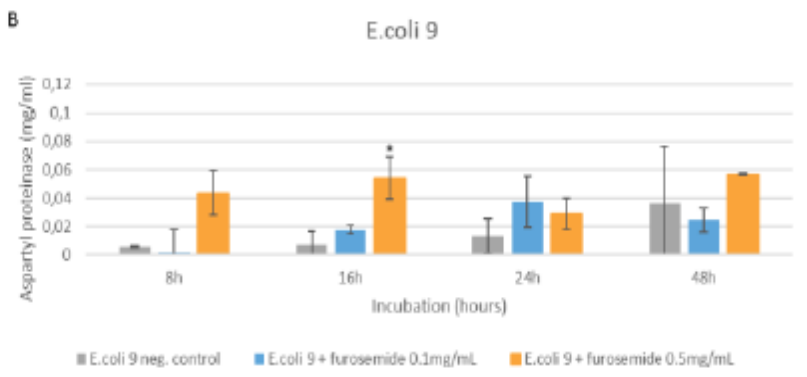

Figure 3 (A, B, C). Excretion of aspartyl proteinase was increased in E. coli strains at different incubation times under treatment of furosemide.

A: Furosemide $(0.5 \mathrm{mg} / \mathrm{mL})$ increased aspartyl proteinase excretion in E. coli 8 after 16 hours of incubation. B: The similar results were observed for E. coli 9 strain. C: Metabolic activity of $E$. coli control under furosemide treatment increased after $8 \mathrm{~h}(0.5 \mathrm{mg} / \mathrm{mL})$ and $16 \mathrm{~h}(0.1$

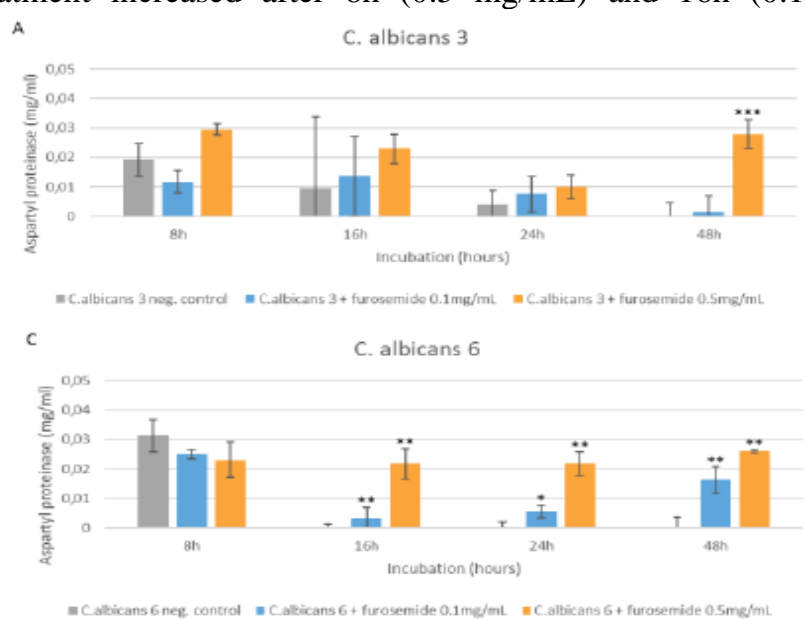

$\mathrm{mg} / \mathrm{mL}$ ). Experiments were performed in triplicates. Mean \pm $\mathrm{SD}$ are plotted in the bar charts, with asterisks that indicate levels of statistical significance $(* p<0.05, * * p<0.01$, and $* * * p<0.001)$.

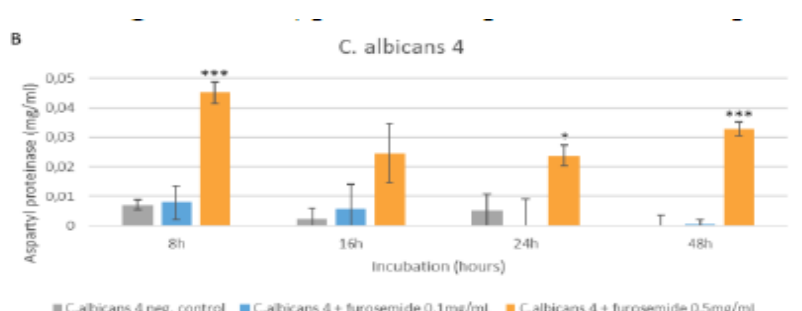

Figure 4 (A, B, C). Excretion of aspartyl proteinase was increased in C. albicans strains at different incubation times under treatment of furosemide.

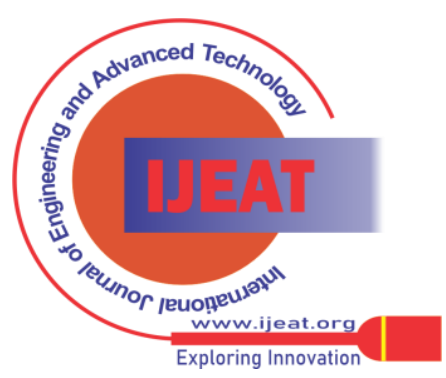


A: Significant increase of aspartyl proteinase excretion in $C$. albicans 3 observed after 48 hours of incubation with furosemide. B: Enhanced excretion in C. albicans 4 throughout the entire

incubation in dose-dependent fashion. C: Furosemide-induced metabolic upregulation of C. albicans 6 started after 16 hours and persisted throughout the remaining incubation. Experiments were performed in triplicates. Mean \pm SD are plotted in the bar charts, with asterisks that indicate levels of statistical significance $\left({ }^{*} p<0.05,{ }^{* *} p<0.01\right.$, and $* * * p<0.001)$.

\section{Effects of furosemide of biofilm formation}

Through metabolic upregulation, drug furosemide may also increase the biofilm forming capacities of $E$. coli and $C$. albicans strains. For C. albicans 4 strain, a weak biofilm formation was observed after 16 hours of incubation. However, this strain formed the same biofilm earlier with furosemide, after 8 hours of incubation. In addition, this strain became a moderate biofilm former after 24 and 48 hours of incubation with furosemide of $0,5 \mathrm{mg} / \mathrm{mL}$. Non-biofilm former, C. albicans 6 gained that ability after 48 hours with furosemide of lower concentration, and after 16 hours of incubation with furosemide of the higher concentration (Table 1). Similar dose-dependent effect was observed for E. coli strains. E. coli 9 and E. coli 8 formed weak biofilm after 8 and 16 hours of incubation, respectively. The moderate biofilm formation of $E$. coli 8 was observed after 48 hours with furosemide of $0.1 \mathrm{mg} / \mathrm{mL}$ concentration, and after 24 hours of incubation with furosemide of higher, $0.5 \mathrm{mg} / \mathrm{mL}$, concentration. For E. coli 9 strain treated with furosemide of higher concentration, the moderate biofilm formation was evident after 48 hours of incubation compared to non-treatment and furosemide of lower concentration groups that remained to produce weak biofilm. Non-biofilm former, $E$. coli control became weak biofilm former after 48 hours of incubation at $37^{\circ} \mathrm{C}$ (Table 2 ).

Table 1. Biofilm forming capacity of $C$. albicans strains

\begin{tabular}{|l|l|l|l|l|}
\hline Biofilm formation & $\mathbf{8 h}$ & $\mathbf{1 6 h}$ & $\mathbf{2 4 h}$ & $\mathbf{4 8 h}$ \\
\hline C. albicans 3 & - & - & + & + \\
\hline C. albicans $3+$ furosemide $0.1 \mathrm{mg} / \mathrm{mL}$ & - & - & + & + \\
\hline C. albicans $3+$ furosemide $0.5 \mathrm{mg} / \mathrm{mL}$ & - & - & + & - \\
\hline C. albicans 4 & - & + & + & + \\
\hline C. albicans $4+$ furosemide $0.1 \mathrm{mg} / \mathrm{mL}$ & + & + & + & + \\
\hline C. albicans $4+$ furosemide $0.5 \mathrm{mg} / \mathrm{mL}$ & + & + & ++ & ++ \\
\hline C. albicans 6 & - & - & - & - \\
\hline C. albicans $6+$ furosemide $0.1 \mathrm{mg} / \mathrm{mL}$ & - & - & - & + \\
\hline C. albicans $6+$ furosemide $0.5 \mathrm{mg} / \mathrm{mL}$ & - & + & + & + \\
\hline
\end{tabular}

Legend: (-) no biofilm; $(+)$ weak biofilm; $(++)$ moderate biofilm; $(+++)$ strong biofilm.

Table 2. Biofilm forming capacity of $E$. coli strains

\begin{tabular}{|l|l|l|l|l|}
\hline Biofilm formation & $\mathbf{8 h}$ & $\mathbf{1 6 h}$ & $\mathbf{2 4 h}$ & $\mathbf{4 8 h}$ \\
\hline E. coli 8 & - & + & + & + \\
\hline E. coli $8+$ furosemide $0.1 \mathrm{mg} / \mathrm{mL}$ & - & + & + & ++ \\
\hline E. coli $8+$ furosemide $0.5 \mathrm{mg} / \mathrm{mL}$ & - & + & ++ & ++ \\
\hline E. coli 9 & + & + & + & + \\
\hline E. coli $9+$ furosemide $0.1 \mathrm{mg} / \mathrm{mL}$ & - & + & + & + \\
\hline E. coli $9+$ furosemide $0.5 \mathrm{mg} / \mathrm{mL}$ & - & + & + & ++ \\
\hline E. coli control & - & - & - & - \\
\hline $\begin{array}{l}\text { E. coli control }+ \text { furosemide } 0.1 \\
\mathrm{mg} / \mathrm{mL}\end{array}$ & - & - & - & ++ \\
\hline $\begin{array}{l}\text { E. coli control }+ \text { furosemide } 0.5 \\
\mathrm{mg} / \mathrm{mL}\end{array}$ & - & - & - & + \\
\hline
\end{tabular}

Legend: (-) no biofilm; (+) weak biofilm; $(++)$ moderate biofilm; $(+++)$ strong biofilm.

\section{DISCUSSION}

E. coli is recognized as the most frequent cause of UTIs, while $C$. albicans is the most prevalent fungal urogenital pathogen [13]. Both primarily colonize gastrointestinal tract, but they may sporadically migrate to other systems as well. Most infections are endogenous, meaning that $E$. coli and $C$. albicans, constituents of normal microbial flora, take the new opportunity of dysbiosis as the advantage to cause infections. These situations are increased in hospitalized and immunocompromised patients [14-17]. Moreover, numerous studies associate increased pathogenicity of microbiota with certain hormonal influences and drug therapies, including antibiotics $[18,19]$. When found in a new environment, microbes may acquire features allowing them to survive and eventually to progress. A special adaptation is microbial organization into communities called biofilm. Biofilm provides microbes with numerous benefits. It allows them to colonize various surfaces, and protects them from the environment, including defense against host immune system and antimicrobial therapeutics [20,21]. In addition, microbes produce proteases, a huge group of enzymes playing important roles in microbial life, stress response and pathogenicity [22]. They also represent an important protein component of the biofilm [23]. Extracellular proteases are secreted principally to provide food for the cells, but microbes may use them in the processes of cell colonization, penetration and antimicrobial peptide cleavage. One of the most significant extracellular proteases is secreted aspartyl proteinase [24]. In C. albicans, aspartyl proteinase production is linked to several virulence features such as hyphal formation, adhesion, and phenotypic switching $[25,26]$. It has also been reported a higher aspartyl proteinase excretion in virulent Candida species in comparison to less virulent species [27]. Additional study has shown the importance of aspartyl proteinase for microbial cell-cell contact and biofilm formation [28].

Several types of loop diuretics exist, along with furosemide, bumetanide, torsemide, and ethacrynic acid. They are characterized with different pharmacokinetics and pharmacodynamics. In general, they have rapid absorption after oral administration, achieving maximum concentrations within half to two hours. Oral bioavailability of torsemide and bumetanide surpass $80 \%$, compared to $50 \%$ of that for furosemide. However, gastrointestinal absorption of furosemide is slower than its elimination, making its duration of action longer [2]. There are several studies demonstrating a tight connection between diuretics use and their effect on microbiota, including spontaneous bacterial peritonitis episodes in cirrhotic patients and even anaphylactic reactions in some patients $[3,4]$. Nevertheless, there are no available studies about potential effects of diuretics on microbiota of urogenital tract. Since the administration of diuretics can cause gender-related differences by which women need lower doses of diuretics [5,6], we focused our study on microbial strains isolated from female patients suffering from UTI as more dominant type of infections in this population $[7,8]$.We investigated the effect of furosemide on microbial growth,

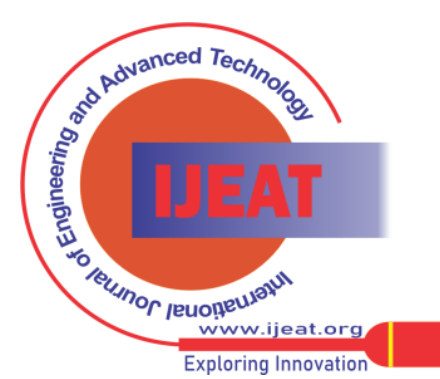


metabolism and biofilm formation. Furosemide, as a member of loop diuretics, is commonly used drug in clinical settings, primarily in the treatment of high blood pressure, edema and several other cardiovascular, kidney and liver diseases [29].In developed countries, cardiovascular diseases are among the most common ones and their incidence is constantly increasing [30,31]. Consequently, a number of people using furosemide is on the rise. Therefore, a potential stimulatory effect of this drug on microbial flora would represent interesting translational information. Indeed, our results suggest that furosemide is able to increase the microbial virulence and even turn commensal microbes into opportunistic pathogens. Additionally, the results propose that virulent enzyme aspartyl proteinase might act as a signal molecule for the biofilm formation and thus help microbes to increase their chances of survival and progression. E. coli strains increased their aspartyl proteinase excretion under furosemide treatment. This effect was notably observed after 16 hours of incubation at $37^{\circ} \mathrm{C}$ (Figure 3). Similarly, all tested C. albicans strains were metabolically upregulated under furosemide treatment (Figure 4). This drug has also increased the biofilm forming capacities of E. coli and C. albicans strains. Interestingly, non-biofilm former strains, $E$. coli control and C. albicans 6 gained the capacity of biofilm formation when treated with furosemide. E. coli control became a weak biofilm former after 48 hours of incubation (Table 1). C. albicans 6 became a weak biofilm former in dose-dependent fashion, after 48 hours incubation with furosemide in concentration of $0.1 \mathrm{mg} / \mathrm{mL}$ and after 16 hours of incubation with furosemide in concentration of $0.5 \mathrm{mg} / \mathrm{mL}$ (Table 2). To our knowledge, this represents the first association of the loop diuretic drug with increased microbial virulence. Similar findings were observed in another study on insulin and diabetes-related E. coli pathogenesis [10]. Moreover, several drugs have been associated with increased aspartyl proteinase excretion in C. albicans, including analgesic medications paracetamol, analgin, brufen and difen, as well as iron supplements. Interestingly, antibiotic ampicillin stimulates the growth of C. albicans in vitro, but it is not capable of inducing aspartyl proteinase excretion [32].

\section{CONCLUSION}

Since secreted aspartyl proteinase serves as one of the key virulence factors involved in the microbial pathogenesis, they represent a potential target for new antimicrobial drug development. Moreover, enzymatic activity of secreted aspartyl proteinase may be utilized as a component of biosensor chips used for microbial detection. This detection of microbial-specific enzymatic activity represents a rapid and inexpensive screening method using very small amounts of clinical samples [33,34]. In conclusion, our results show that drug furosemide, in addition to its primary effects for which it is prescribed, may act as the signal molecule for the biofilm formation, and thus, increase the microbial pathogenicity. These findings also indicate additional demand for research on microbial metabolic activity and their proteins as potential virulent factors and modulators of microbial pathogenicity.

\section{ACKNOWLEDGMENT}

This study was supported by FUNGITECT project funding (European Commission) and Ministry of Education, Science and Youth of Sarajevo Canton - Sector for Higher Education, Science and Youth, Bosnia and Herzegovina.

\section{REFERENCES}

1. Wargo, K.A.; Banta, W.M. A comprehensive review of the loop diuretics: Should furosemide be first line? Ann. Pharmacother. 2009, 43, 1836-1847.

2. Ellison, D.H. Clinical pharmacology in diuretic use. Clin. J. Am. Soc Nephrol. 2019, 14, 1248-1257, doi:10.2215/CJN.09630818.

3. Gahlot, D.; Talukdar, R.; Seth, V.; Manohar, M. Anaphylactic shock with intravenous furosemide: a rare undesired effect. MAMC J. Med. Sci. 2020, 6, 60, doi:10.4103/mamcjms.mamcjms_13_20.

4. Solà, R.; Andreu, M.; Coll, S.; Vila, M.C.; Oliver, M.I.; Arroyo, V. Spontaneous bacterial peritonitis in cirrhotic patients treated using paracentesis or diuretics: Results of a randomized study. Hepatology 1995, 21, 340-344, doi:10.1002/hep.1840210212.

5. Gu, Q.; Burt, V.L.; Paulose-Ram, R.; Dillon, C.F. Gender differences in hypertension treatment, drug utilization patterns, and blood pressure control among US adults with hypertension: Data from the National Health and Nutrition Examination Survey 1999-2004. Am. J. Hypertens. 2008, 21, 789-798, doi:10.1038/ajh.2008.185.

6. Rasmussen, T.P.; Williford, N.N.; Dezorzi, C.; Hammoud, A.; Boyle, B.J.; Zhou, Y.; Ten Eyck, P.; Gebska, M.A. Women Hospitalized for Acute on Chronic Decompensated Systolic Heart Failure Receive Less Furosemide Compared to Men. Cardiol. Res. Pract. 2019, 2019, doi:10.1155/2019/1505142.

7. Foxman, B. Urinary tract infection syndromes. Occurrence, recurrence, bacteriology, risk factors, and disease burden. Infect. Dis. Clin. North Am. 2014, 28, 1-13.

8. Butler, C.C.; Hawking, M.K.D.; Quigley, A.; McNulty, C.A.M Incidence, severity, help seeking, and management of uncomplicated urinary tract infection: A population-based survey. Br. J. Gen. Pract 2015, 65, e702-e707.

9. Brannon, J.R.; Dunigan, T.L.; Beebout, C.J.; Ross, T.; Wiebe, M.A.; Reynolds, W.S.; Hadjifrangiskou, M. Invasion of vaginal epithelial cells by uropathogenic Escherichia coli. Nat. Commun. 2020, 11, doi:10.1038/s41467-020-16627-5.

10. Kamelija, M.-T.; Izet, E.; Nadira Ibrišimović, M.; Mirza, I. Insulin Acts as Stimulatory Agent in Diabetes-Related Escherichia Coli Pathogenesis. Int. J. Diabetes Clin. Res. 2018, 5, doi:10.23937/2377-3634/1410098.

11. Söderström, C.M.; Fagerberg, S.K.; Brogaard, M.B.; Leipziger, J.; Skals, M.; Praetorius, H.A. Loop Diuretics Diminish Hemolysis Induced by $\alpha$-Hemolysin from Escherichia coli. J. Membr. Biol. 2017, 250, 301-313, doi:10.1007/s00232-017-9963-0.

12. Behzadi, P.; Behzadi, E.; Ranjbar, R. Urinary tract infections and Candida albicans. Cent. Eur. J. Urol. 2015, 68, 96-101, doi:10.5173/ceju.2015.01.474.

13. Flores-Mireles, A.L.; Walker, J.N.; Caparon, M.; Hultgren, S.J. Urinary tract infections: Epidemiology, mechanisms of infection and treatment options. Nat. Rev. Microbiol. 2015, 13, 269-284.

14. Li, F.; Song, M.; Xu, L.; Deng, B.; Zhu, S.; Li, X. Risk factors for catheter-associated urinary tract infection among hospitalized patients: A systematic review and meta-analysis of observational studies. J. Adv. Nurs. 2019, 75, 517-527.

15. Aloush, S.M.; Al Qadire, M.; Assmairan, K.; Al Sheikh, H.; Mosbah, A.; Hussien, H.; Al Bzoor, B. Risk factors for hospital-acquired non-catheter-associated urinary tract infection. J. Am. Assoc. Nurse Pract. 2019, 31, 747-751, doi:10.1097/JXX.0000000000000175.

16. Fünfstück, R.; Nicolle, L.E.; Hanefeld, M.; Naber, K.G. Urinary tract infection in patients with diabetes mellitus. Clin. Nephrol. 2012, 77 40-48, doi:10.5414/CN107216.

17. Marcus, N.; Ashkenazi, S.; Samra, Z.; Cohen, A.; Livni, G. Community-acquired enterococcal urinary tract infections in hospitalized children. Pediatr. Nephrol. 2012, 27, 109-114, doi:10.1007/s00467-011-1951-5.

18. Arinzon, Z.; Shabat, S.; Peisakh, A.; Berner, Y. Clinical presentation of urinary tract infection (UTI) differs with aging in women. Arch. Gerontol. Geriatr. 2012, 55, 145-147, doi:10.1016/j.archger.2011.07.012.

19. Waller, T.A.; Pantin, S.A.L.; Yenior, A.L.; Pujalte, G.G.A. Urinary Tract Infection Antibiotic Resistance in the United States. Prim. Care Clin. Off. Pract. 2018, 45, 455-466.

Published By:

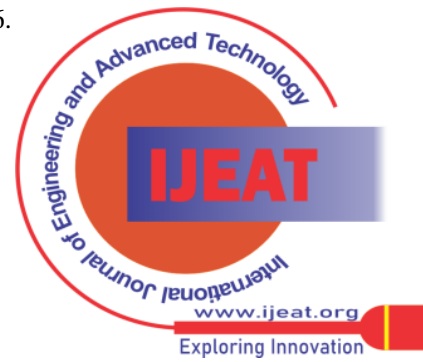


20. Berlanga, M.; Guerrero, R. Living together in biofilms: The microbial cell factory and its biotechnological implications. Microb. Cell Fact. 2016, 15, 165.

21. Hall, C.W.; Mah, T.F. Molecular mechanisms of biofilm-based antibiotic resistance and tolerance in pathogenic bacteria. FEMS Microbiol. Rev. 2017, 41, 276-301.

22. Culp, E.; Wright, G.D. Bacterial proteases, untapped antimicrobial drug targets. J. Antibiot. (Tokyo). 2017, 70, 366-377.

23. Flemming, H.C.; Wingender, J. The biofilm matrix. Nat. Rev. Microbiol. 2010, 8, 623-633.

24. Hube, B.; Naglik, J. Candida albicans proteinases: Resolving the mystery of a gene family. Microbiology 2001, 147, 1997-2005.

25. Monod, M.; Borg-von Zepelin, M. Secreted proteinases and other virulence mechanisms of Candida albicans. Chem. Immunol. 2002, 81 114-128.

26. Naglik, J.; Albrecht, A.; Bader, O.; Hube, B. Candida albicans proteinases and host/pathogen interactions. Cell. Microbiol. 2004, 6, 915-926.

27. Naglik, J.R.; Challacombe, S.J.; Hube, B. Candida albicans Secreted Aspartyl Proteinases in Virulence and Pathogenesis. Microbiol. Mol. Biol. Rev. 2003, 67, 400-428, doi:10.1128/mmbr.67.3.400-428.2003.

28. Mendes, A.; Mores, A.U.; Carvalho, A.P.; Rosa, R.T.; Samaranayake, L.P.; Rosa, E.A.R. Candida albicans biofilms produce more secreted aspartyl protease than the planktonic cells. Biol. Pharm. Bull. 2007, 30 , 1813-1815, doi:10.1248/bpb.30.1813.

29. Boles Ponto, L.L.; Schoenwald, R.D. Furosemide (Frusemide) A Pharmacokinetic/Pharmacodynamic Review (Part I). Clin. Pharmacokinet. 1990, 18, 381-408, doi:10.2165/00003088-199018050-00004.

30. Xu, J.; Murphy, S.L.; Kochanek, K.D.; Arias, E. Mortality in the United States, 2018 Key findings Data from the National Vital Statistics System; 2018;

31. Van Camp, G. Cardiovascular disease prevention. Acta Clin. Belgica Int. J. Clin. Lab. Med. 2014, 69, 407-411.

32. Ibrišimović, M.; Ibrišimović-Mehmedinović, N.; Dedić, J.; Kesić, A.; Marić, S.; Šestan, A. Effects of various metal and drug agents on excretion of enzyme aspartyl proteinase in Candida albicans and its role in human physiological processes. In Proceedings of the IFMBE Proceedings; Springer Verlag, 2017; Vol. 62, pp. 731-735.

33. Ahmed, A.; Rushworth, J. V.; Hirst, N.A.; Millner, P.A. Biosensors for whole-cell bacterial detection. Clin. Microbiol. Rev. 2014, 27, 631-646, doi:10.1128/CMR.00120-13.

34. Mehmedinović, N.I.; Ibrišimović, M.; Dedić, J.; Kesić, A.; Hodžić, Z.; Hadžigrahić, N. Early detection of fungal pathogens in patients with immunodeficiency involving a novel biosensor technology. Int. J. Dev. Res. 2020, 10, 34939-34942.

\section{AUTHORS PROFILE}

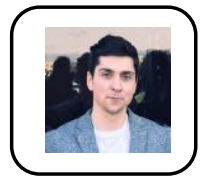

Amar Balihodžić, is medical doctor and research fellow at Sarajevo Medical School, at University Sarajevo School of Science and Technology in Sarajevo, Bosnia and Herzegovina.

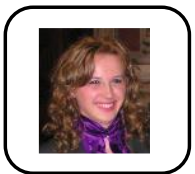

Nadira Ibrišimović Mehmedinović, is associate professor at Department of Chemistry, Faculty of Natura Sciences and Mathematics, University of Tuzla, Tuzla, Bosnia and Herzegovina. Nadira Ibrišimović Mehmedinović is author of 24 scientific publications,

four books, and two patents.

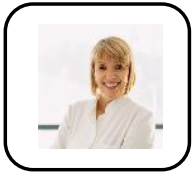

Suada Tinjić, is gynecologist and director of Gynecology Polyclinc "Korak do života" in Tuzla, Bosnia and Herzegovina. Dr. Suada Tinjić has $\mathrm{PhD}$ in medicine, and is author of 13 publications, and co-author of several books.

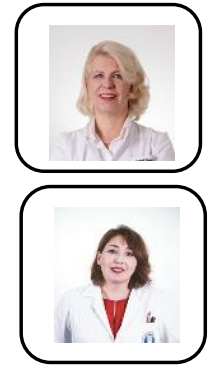

Semira Galijašević, is full professor at Sarajevo Medica School, at University Sarajevo School of Science and Technology in Sarajevo, Bosnia and Herzegovina.

Kamelija Madacki-Todorović, is senior teaching assistant at Sarajevo Medical School, at University Sarajevo School of Science and Technology in Sarajevo, Bosnia and Herzegovina.

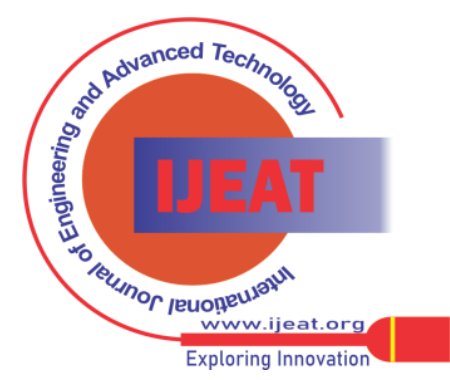
Science and Technology in Sarajevo, Bosnia and Herzegovina, and also works as embryologist and cytoscreener-supervisor in Gynecology Polyclinc "Korak do života" in Tuzla, Bosnia and Herzegovina. Mirza books, and one patent. edical School, at University Sarajevo School of Ibrišimović is author of 23 scientific publications, four
Izet Eminović, is full professor at Faculty of Natural

Lejla Hasanbegović, is research investigator and Biochemical-Immunological-Hemathological Herzegovina.

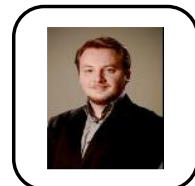

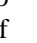
Science and Mathematics, University of Sarajevo, "Medical Laboratory" Ilidža, Sarajevo, Bosnia and 